\title{
QUANTITATIVE ULVA PROLIFERA BLOOM MONITORING BASED ON MULTI-SOURCE SATELLITE OCEAN COLOR REMOTE SENSING DATA
}

\author{
ZHENG, H. Y. ${ }^{1}-$ LIU, Z. ${ }^{1 *}-$ CHEN, B. ${ }^{2}-\mathrm{XU}, \mathrm{H} .{ }^{3}$ \\ ${ }^{1}$ College of Ocean Science and Engineering, Shandong University of Science and Technology, \\ Qingdao 266590, China \\ ${ }^{2}$ Guangxi Key Laboratory of Marine Environment Science, Guangxi Academy of Science, Nanning \\ 530007, China \\ ${ }^{3}$ College of Geomatics, Shandong University of Science and Technology, Qingdao 266590, China \\ *Corresponding author \\ e-mail:zhliu01@126.com
}

(Received $9^{\text {th }}$ Jan 2020; accepted $6^{\text {th }}$ May 2020)

\begin{abstract}
Since 2007, a large-scare green macroalgae bloom of Ulva prolifera has occurred every year in the Yellow Sea, and satellite ocean color remote sensing monitoring of such event is an effective technical method with important application value. For the Moderate Resolution Imaging Spectroradiometer (MODIS), Geostationary Ocean Color Imager (GOCI), Sentinel-3 Ocean and Land Colour Instrument (OLCI), Landsat8 Operational Land Imager (OLI) and Gaofen satellite (GF1) multispectral satellite data of the study area, the bloom was monitored based on spectral band difference algorithms and band-ratio algorithms. In view of the threshold selection of the detection, the scaled algae index (SAI) is less sensitive to the environment and shows accurate stability. For the five satellite ocean color sensors, this study compared their ability to monitor algal bloom on spatial and temporal scales. On the spatial scale, quantitative results of each data are specifically compared. Low spatial resolution data was found to overestimate the blooming area. On the time scale, GOCI can best monitor the dynamic changes of bloom, and the composites of algae and sea surface wind shows the dynamic evolution of blooming event in the range from May to July 2017.
\end{abstract}

Keywords: green tide, green macroalgae bloom, NDVI, Scaled Algae Index (SAI), Floating Algae Index (FAI)

\section{Introduction}

Ulva prolifera blooms (previously known as Enteromorpha prolifera) is defined as an ecological anomaly of massive green macroalgae exploding and accumulating under specific environmental conditions (Liang et al., 2008). In China, a large amount of waste on the vast coastal beaches of Jiangsu Province is thrown into the sea every spring, and the culture of the growing seaweed is polluted, which has spawned thousands of tons of $U$. prolifera (Hu et al., 2010b; Keesing et al., 2011; Naihao and Zhimeng, 2010). According to the Chinese marine bulletin, large-scale green algal blooms occur every year, often floating on the surface of scum, covered with biological or exudate beaches, with a range of up to $10,000 \mathrm{~km}^{2}$. The $U$. prolifera disaster will cause huge losses to China's economy and will also cause damage to marine resources such as benthic animals, aquatic plants, and underwater resources (Liu et al., 2009; Shimada et al., 2008).

Ocean color remote sensing is a passive measurement technique that utilizes visible and near-infrared bands. Compared with the surrounding seawater, the increase of algal 
biomass leads to significant changes in satellite radiation. The law of light propagation is similar to that of common vegetation. There is a clear reflection peak near the green band at $555 \mathrm{~nm}$ and a distinct absorption peak near the red light at $680 \mathrm{~nm}$. In the infrared band, the reflectance rises sharply to form a "red edge". At $960 \mathrm{~nm}$ and $1100 \mathrm{~nm}$, there is an absorption peak due to water absorption (Xiao et al., 2017). With the increase of algal biomass, the reflectance of $U$. prolifera is shifted upward as a whole. Through the ocean color satellite data, we can obtain a series of bio-optical parameters such as chlorophyll concentration, sea surface temperature, fluorescence height, and seawater optical diffuse attenuation coefficient. In addition to the scientific data needed in these biogeochemical studies, ocean color remote sensing can provide near real-time monitoring of global organisms for more than 20 years. This long-term sequence data can be used to invert the evolution of floating algae and analyze timespace transformation.

Since the late 1970s, the increased demand for effective environmental monitoring for the coast has led to significant advances in the study of ocean color algorithms. Based on the difference between the spectrum of algae and surrounding seawater, various algorithms have been developed to help and monitor the blooms of U. prolifera. Depending on the specific spectral characteristics of $U$. prolifera, the algal patches and other features can be effectively classified by supervised or unsupervised classification; the spectral band difference algorithms and the band-ratio algorithms obtained by empirical model using in situ data sets such as chlorophyll and reflectivity is widely used in the detection of this events; the bio-optical model based on solid theoretical basis and strict equations is robust in algal classification applications. In 2008, $\mathrm{Hu}$ and He et al. analyzed the $U$. prolifera bloom along the coast of Qingdao during the Olympic Games using the Normalized Vegetation Index (NDVI) (Hu and He, 2008). In 2009, Hu et al. proposed a Floating Algae Index (FAI) and explored the origin of floating algae using MODIS's 2007-2013 data (Hu et al., 2010a; Hu, 2009). In 2016, Zhang Hailong et al. also proposed the Multispectral Green Tide Index (MGTI) based on GF/WFV (wide field-of-view) and HJ CCD (Huanjing satellite charge coupled device) data, and found that MGTI's overall satellite detection results for China are good (Zhang et al., 2016). The qualitative detection of blooms by ocean color remote sensing has been developed more fully (Blondeau-Patissier et al., 2014).

A wide variety of satellite sensors provide solid data support for blooms monitoring, and the use of multi-source data to monitor algae is becoming a research hotspot. Cui et al compared the ability of MODIS/Terra (EOS AM), HJ-1/CCD, Environmental Satellite (ENVISAT) Advanced Synthetic Aperture Radar (ASAR) data to detect massive green macroalgae bloom, and obtained the conclusion that spatial resolution is the main influence factor for the area of detection bloom (Cui et al., 2012). The remote sensing data of the ocean color satellites such as MODIS/Aqua (EOS PM), COMS (Communications, Ocean and Meteorological Satellite)/GOCI, Sentinel-3/OLCI, Landsat8/OLI and GF1/WFV used in this study have different spatial resolution, spectral resolution and time resolution, and also have difference with spatial coverage. What is the capability of these satellite sensors to monitor $U$. prolifera blooms? Which sensor has better performance for algal blooms detection? Is there a way to improve the performance of blooms detection? Is the effect monitored by different optical algorithms consistent? Based on the above five kinds of remote sensing data, this study analyzed the characteristics of the algorithm for qualitative monitoring, discussed the threshold selection of quantitative detection of $U$. prolifera blooms. We used the mixed 
pixel decomposition for area statistics, and compared a variety of data to detect the performance of algae on the spatial and temporal scales.

\section{Materials}

\section{Study area}

The Yellow Sea is located between the Chinese mainland and the Korean peninsula, with a latitude and longitude range of $32^{\circ} \mathrm{N}-37^{\circ} \mathrm{N}$ and $119^{\circ} \mathrm{E}-123^{\circ} \mathrm{E}$. Habitually, the Yellow Sea is divided into two parts, the North Yellow Sea and the South Yellow Sea, with a line connecting the Chengshanjiao of Jiaodong Peninsula to the Changshanchuan of North Korea. The study area selected in this paper is located in the South Yellow Sea (e.g. Fig. 1). The sea area is rich in water mass, with coastal currents moving southward along the mainland, black tide branches entering through the Tsushima Strait, and Yangtze River freshwater flowing from the Yangtze River estuary to Jeju Island. According to the China's marine bulletin, from May to July 2017, the U. prolifera disaster affected the sea area near the South Yellow Sea, and the coverage area and distribution area reached the maximum on June 19, which were $281 \mathrm{~km}^{2}$ and $29522 \mathrm{~km}^{2}$ respectively.
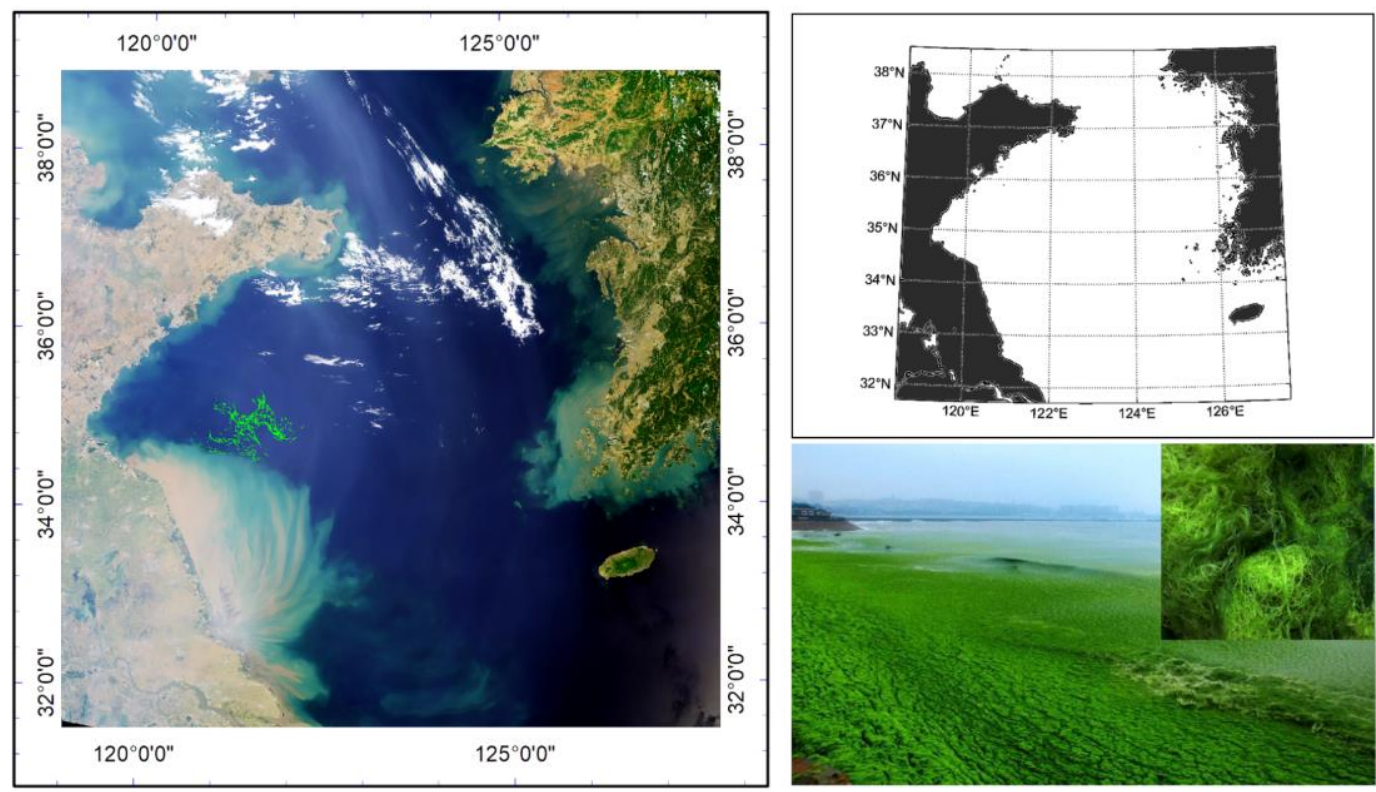

Figure 1. Overview of the study area, the lower right is an example of green U. prolifera bloom

\section{Data}

The important advances in the design techniques of the second and third generation ocean color satellite sensors have greatly improved the ocean color algorithm, and then the visualization of satellite images can accurately monitor blooms events such as $U$. prolifera bloom in coastal waters. In order to study the effect of the resolution on quantitative estimation of blooming area, this paper selects Aqua/MODIS with $1000 \mathrm{~m}$ resolution, COM/GOCI with $500 \mathrm{~m}$ resolution, sentinel-3/OLCI with $300 \mathrm{~m}$ resolution, Landsat8/OLI with $30 \mathrm{~m}$ resolution, GF1/WFV with a resolution of $16 \mathrm{~m}$, five different 
spatial resolution data, they also have different spectral resolutions (e.g. Table 1) (the five images are imaged on May 27, 2017). The surface wind speed at $0.25^{\circ}$ horizontal resolution are obtained from the Advanced Microwave Scanning Radiometer for Earth Observing System (AMSR). The surface wind vectors at $0.25^{\circ}$ horizontal resolution are obtained from the Cross Calibrated Multi-Platform (CCMP) which provides consistent, gap-free long-term timeseries of the surface wind vector analysis field from July 1987 to May 2016.

Table 1. Sensor property analysis

\begin{tabular}{c|c|c|c|c|c}
\hline Instrument & Agency/spacecraft & $\begin{array}{c}\text { Spatial } \\
\text { resolution (m) }\end{array}$ & Width (km) & $\begin{array}{c}\text { Mission } \\
\text { life }\end{array}$ & Revisit time \\
\hline WFV & GF1 & 16 & $\begin{array}{c}800 \text { (Four- } \\
\text { Taiwan Union) }\end{array}$ & $\begin{array}{c}2013- \\
\text { present }\end{array}$ & 4 days \\
\hline OLI & Landsat8 & 30 & 185 & $\begin{array}{c}2013- \\
\text { present }\end{array}$ & 16 days \\
\hline OLCI & ESA-Copernicus/Sentinel-3 & 300 & 1270 & $\begin{array}{c}2016- \\
\text { present }\end{array}$ & $\begin{array}{c}\text { Less than } \\
2 \text { days }\end{array}$ \\
\hline GOCI & KIOST/COMS & 500 & 2500 & $\begin{array}{c}2010- \\
\text { present }\end{array}$ & $1 \mathrm{~h}$ \\
\hline MODIS & NASA/Terra; Aqua & $1000 \& 500 \& 200$ & 2330 & $\begin{array}{c}1999- \\
\text { present; } \\
2002- \\
\text { present }\end{array}$ & 1 day \\
\hline
\end{tabular}

Moderate Resolution Imaging Spectroradiometer (MODIS) is currently mounted on the Earth Observation System (EOS) Terra (AM) and Aqua (PM) satellites to transmit real-time data to the world via the X-band. Its main goal is to achieve a comprehensive view of solar radiation, the atmosphere, the ocean and the land from a single series of polar orbital space platforms. MODIS contains 36 bands, including 20 bands of visible light to short-wave infrared, 16 bands of thermal infrared, spatial resolution of 1-2 band of $250 \mathrm{~m}, 3-7$ band of $500 \mathrm{~m}$, and the remaining bands of $1000 \mathrm{~m}$. The Geostationary Ocean Color Imager (GOCI) is the world's first geostationary orbit satellite imaging sensor. The GOCI is loaded on the Communications, Ocean and Meteorological Satellite (COMS) of South Korea launched in June 2010 and operated by the Korea Ocean Satellite Center (KOSC) to observe or monitor the color of the water surrounding the Korean peninsula. The OLCI is mounted on the sentinel-3 satellite. The Sentinel-3 is a polar-orbit, multi-sensor satellite system that includes sensors and optical instruments and developed by the European Space Agency as part of the Copernicus Programme to better manage the environment and understand climate change. The OLI is mounted on the American Earth observation satellite Landsat8, which runs from a near-polar circular orbit synchronized with the sun to ensure imaging of moderate solar elevations in the mid-latitudes of the Northern Hemisphere. OLI uses push-broom sensors and uses NASA's (National Aeronautics and Space Administration) technology in Advanced Land Imager sensors, which helps reduce moving parts and improve ground information. Four 16-m resolution multi-spectral cameras WFV are mounted on China's GF1. Combined with multi-spectral, high spatial resolution and high temporal resolution optical remote sensing technology, it has promoted China's satellite engineering. 
Remote sensing images are usually recorded with dimensionless digitized Digital Number (DN) values, and the true reflectivity is required for the algal quantization calculation, so radiometric calibration and atmospheric correction are required. The purpose of radiometric calibration is to convert the DN value into radiance. The atmospheric correction is mainly to eliminate the influence of atmospheric molecules and aerosol scattering on the reflection of the ground object. Before performing these two steps, in order to eliminate terrestrial interference, land mask processing is first performed. Multi-data quantification of algal statistic requires regional matching and therefore requires precise geometric correction to obtain geographic information. Finally, when we analyzed the performance of each resolution data, we can choose good weather condition and the range of the same area covered by the blooming patches is: $34^{\circ} 31^{\prime} 41^{\prime \prime} \mathrm{N}-35^{\circ} 22^{\prime} 17^{\prime \prime} \mathrm{N}, 120^{\circ} 33^{\prime} 23^{\prime \prime} \mathrm{E}-122^{\circ} 14^{\prime} 14^{\prime \prime} \mathrm{E}$.

\section{Methods}

\section{Qualitative analysis}

This section specifically discusses two optical methods of detection: the band-ratio algorithms and spectral band difference algorithms.

The commonly used band ratio forms of blooming events have a ratio vegetation index RVI, a normalized vegetation index (NDVI; Rouse Jr et al., 1974), and a redeveloped enhanced vegetation index (EVI; Baret and Guyot, 1991), all of which utilize the "red edge" that appears in the near-infrared band of algae. The specific form is as follows:

$$
\begin{gathered}
R V I=R_{N I R} / R_{R} \\
N D V I=\left(R_{N I R}-R_{R}\right) /\left(R_{N I R}+R_{R}\right) \\
E V I=G \times\left(R_{N I R}-R_{R}\right) /\left(R_{N I R}+\mathrm{c}_{1} \times R_{R}-c_{2} \times R_{B}+c_{3}\right)
\end{gathered}
$$

In Equations 1-3, $\mathrm{R}_{\mathrm{B}}, \mathrm{R}_{\mathrm{R}}$ and $\mathrm{R}_{\mathrm{NIR}}$ are surface radiation in the blue, red and near infrared bands, respectively, $c_{3}$ is the canopy background adjustment that handles the nonlinear, differential near-infrared, and red radiation transmission through the canopy. $c_{1}$ and $c_{2}$ are coefficients of the aerosol resistance term. It uses blue bands to correct the aerosol effects in the red band. The coefficients adopted in the MODIS-EVI algorithm are; $c_{3}=1, c_{1}=6, c_{2}=7.5$, and $\mathrm{G}$ (gain factor) $=2.5$. The range of NDVI is between -1 and 1 , and the pixels covered by the $\mathrm{U}$. prolifera patches are usually positive, thus distinguishing them from the ocean pixels.

The reflectance spectrum of a mixed pixel with algae changes significantly compared to the surrounding pure seawater. Compared to scattering, absorption varies more rapidly with wavelength, and two adjacent reflection spectral bands may have similar backscattering properties, but are significantly different in absorption, which can be quantified by spectral band differences. Different algorithms can be designed using spectral band differences. It is concluded that several algorithms for detecting algae have similar mathematical expressions.

$\mathrm{Hu}$ et al. proposed the Floating Algae Index (FAI) for macroalgae (greater than $4000 \mathrm{~km}^{2}$ ) based on MODIS data. FAI uses the estimation of the difference between 
reflectance of near-infrared band and the linear baseline of red to short-wave infrared. Zhang Hailong et al. also proposed the Multispectral Green Tide Index (MGTI) based on GF/WFV and HJ/CCD data, defined as the difference between the reflectance of the green band and the linear baseline of the red to blue band. Fluorescence Line Height (FLH) and Maximum Chlorophyll Index (MCI; Gower et al., 2005) for red tide also have the same mathematical form (e.g. Eqs. 4-7).

$$
\begin{gathered}
F A I=R_{N I R}-R_{N I R}^{\prime} \\
R_{N I R}^{\prime}=R_{R}+\left(R_{S W I R}-R_{R}\right) \times \frac{\lambda_{N I R}-\lambda_{R}}{\lambda_{S W I R}-\lambda_{R}} \\
M G T I=R_{G}-R_{G}^{\prime} \\
R_{G}^{\prime}=R_{G}-R_{B}+\left(R_{R}-R_{B}\right) \times \frac{\lambda_{G}-\lambda_{B}}{\lambda_{R}-\lambda_{B}}
\end{gathered}
$$

$R_{B}, R_{G}, R_{R}, R_{N I R}$, and $R_{S W I R}$ are the reflectance of blue, green, red, near-infrared, and short-wave infrared, respectively. For MODIS data, $\mathrm{Hu}$ et al. proposed $\lambda_{\mathrm{R}}=645 \mathrm{~nm}$, $\lambda_{\mathrm{NIR}}=859 \mathrm{~nm}, \lambda_{\mathrm{SWIR}}=1240 \mathrm{~nm}$. Since $1240 \mathrm{~nm}$ results in a lower baseline and a higher FAI value, $1240 \mathrm{~nm}$ instead of $1640 \mathrm{~nm}$ or $2130 \mathrm{~nm}$ is selected for MODIS data. According to GF-WFV data, Zhang Hailong et al. proposed $\lambda_{\mathrm{B}}=475 \mathrm{~nm}, \lambda_{\mathrm{G}}=560 \mathrm{~nm}$, $\lambda_{\mathrm{R}}=660 \mathrm{~nm}$. When the spectral band difference algorithms are applied to GOCI, Sentinel3 and Landsat8, the optimal replacement band is given through comparative analysis.

\section{Threshold selection}

Threshold selection is critical to the impact of green macroalgae bloom monitoring results. For any type of optical sensor, optical algorithms such as NDVI are more or less affected by atmospheric aerosols and turbid waters, and changes in environmental factors on satellite images can lead to irregularities in algorithmic results.

When using traditional single thresholds for classification, because the sea water mass of the Yellow Sea is complex, the degree of turbidity is high, the NDVI values of many seawater pixels are positive, and they are classified as macroalgae pixels, so the region calculation with smaller thresholds contains incorrect seawater pixels, but if the threshold is too large, some algal patches with less biomass will not be detected. We framed two mixed areas (Region A, Region B, e.g. Fig. 2), and performed statistical histogram processing on the NDVI of the two areas, it obtained the bimodal image features (e.g. Fig. 3), which will be unfavorable to quantitative analysis, because it is difficult to choose a single threshold to determine the type of feature. We try to use an image processing algorithm to make the columnar statistics of the algorithm into a single peak shape to achieve semi-automatic threshold selection, which lays a good foundation for our area statistics.

The Scaled Algae Index (SAI) is a semi-automatic image processing algorithm that removes the high variability of images (Garcia et al., 2013). The SAI algorithm is derived from normalized difference algae index (NDAI; Shi and Wang, 2009), based on 
the algorithm results of the spectral band difference algorithms and the band-ratio algorithms obtained in Sections 3.1 and 3.2. By subtracting the local ocean pixel from the desired point, the ocean pixel is reduced to 0 , algae pixels are positive. SAI takes the pixel on the optical algorithm result graph as the center, first selects the template size which match the odd-squared pixel region, performs the median convolution calculations in the spatial domain, and then subtracts the median image from the original algorithm image. (Note: terrestrial and cloud pixels are excluded from convolution calculations).

After the SAI image processing, it was found that the histogram of the region A region $\mathrm{B}$ is centered at 0 and the peaks overlap (e.g. Fig. 3), eliminating the high variability of the image. Three pure ocean regions, a, b, and c were selected, and the mixed seawater region $\mathrm{d}$ were selected, and their histogram distributions were compared (e.g. Fig. 4). After the SAI, the pixel values of the seawater in the regions a, b, and c are balanced, so we can use the tail end of the ocean pixel statistical value as the threshold to extract the algae. For any type of optical image, using the SAI algorithm will reduce the variability of the environment, making the selection of a single threshold always more reliable, and the area results are always more stable and accurate.

\section{Mixed pixel decomposition}

When using the MODIS data of $1000 \mathrm{~m}$ resolution to detect the blooming event, the study area of the algal patches is small, and there is a large number of mixed pixels, which makes large errors based on low resolution data, leading to misjudgment of some features. This study attempts to use the mixed pixel decomposition (Li et al., 2007; Tan et al., 2013) to calculate the blooming area on the basis of qualitatively classifying the algal pixels. The basic features are extracted from the pixels, and the proportion of the calculated features is called hyperspectral unmixing. The basic features are called endmembers, and the endmembers can be understood as pure pixels. The abundance is the proportion of each endmembers. In this paper, we choose two kinds of endmembers of $U$. prolifera and seawater. The maximum image size after SAI treatment is selected as the pure endmember of algae. The specific area calculation is divided into two steps. First, the pixels larger than the threshold in the image are designated as algae pixels, which are less than or equal to the threshold are specified as seawater pixels. The algae pixels are then scaled, and the abundance or scaling ration is limited by the largest pixels in the image.

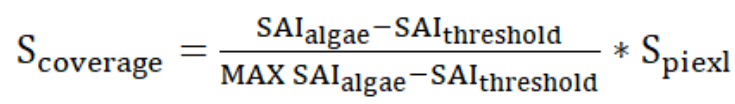

In Equation 8, $\mathrm{S}_{\text {piexl }}$ is the spatial resolution of the sensor (for example, Landsat8 is $30 * 30 \mathrm{~m}^{2}$ ), SAI $\mathrm{I}_{\text {threshold }}$ refers to the threshold obtained in Section 3.3, and MAX SAI algae refers to the pixel value of the largest image after SAI processing.

\section{Results}

\section{Influence of spatial resolution}

From the South Yellow Sea study area, randomly select 12 areas without clouds or less clouds (e.g. Table 2). The MODIS/Aqua, COMS/GOCI, Sentinel-3/OLCI, Landsat8/OLI and GF1/WFV images corresponding to the 12 sub-areas were subjected to atmospheric 
correction, geometric correction, terrestrial mask, and cloud mask pretreatment, then NDVI and SAI threshold methods were used to extract bloom information.

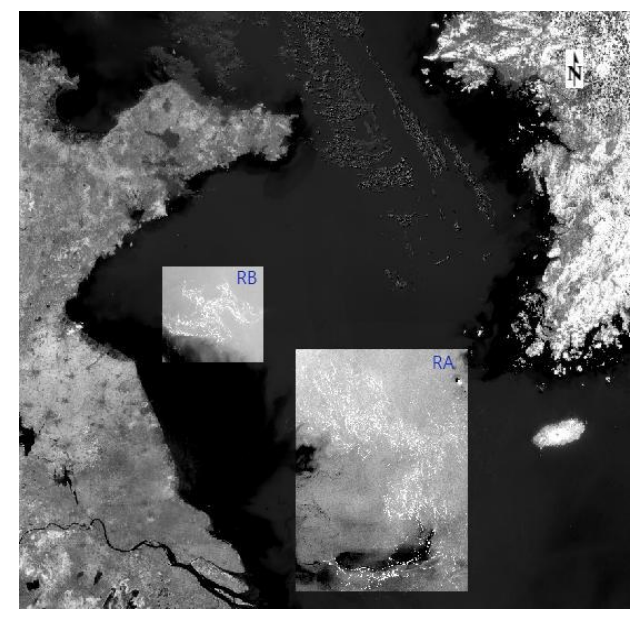

Figure 2. The distribution of region $A\left(31^{\circ} 25^{\prime} 41^{\prime \prime} N-4^{\circ} 28^{\prime} 57^{\prime \prime} N, 122^{\circ} 40^{\prime} 30^{\prime \prime}-125^{\circ} 10^{\prime} 45^{\prime \prime} \mathrm{E}\right)$ and $B\left(35^{\circ} 19^{\prime} 3^{\prime \prime} N-34^{\circ} 29^{\prime} 2^{\prime \prime} N, 120^{\circ} 39^{\prime} 20^{\prime \prime} E-122^{\circ} 11^{\prime} 36^{\prime \prime} E\right)$
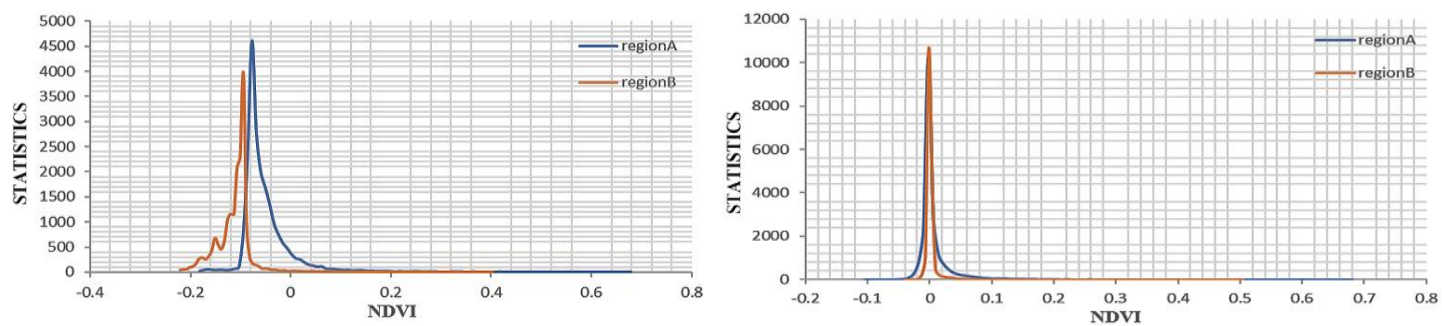

Figure 3. NDVI statistical image of region A and B (take GOCI as an example). Left: statistics without SAI. Right: statistics through SAI
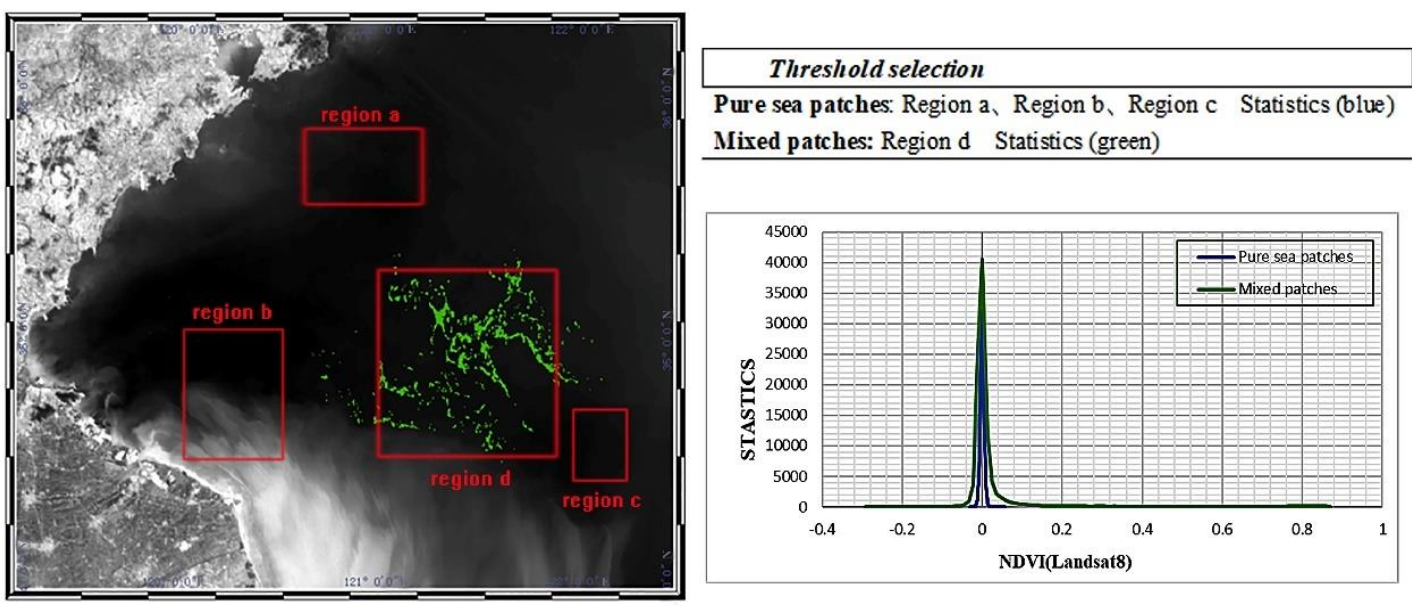

Figure 4. Distribution of region a $\left(35^{\circ} 43^{\prime} 5^{\prime \prime} N-35^{\circ} 59^{\prime} 13^{\prime \prime} N\right.$, $\left.120^{\circ} 24^{\prime} 31^{\prime \prime} E-120^{\circ} 56^{\prime} 4 " \mathrm{E}\right)$, region b $\left(34^{\circ} 33^{\prime} 4^{\prime \prime} \mathrm{N}-35^{\circ} 3^{\prime} 1^{\prime \prime} \mathrm{N}, 119^{\circ} 52^{\prime} 59^{\prime \prime} \mathrm{E}-120^{\circ} 21^{\prime} 58^{\prime \prime} \mathrm{E}\right)$, region c $\left(34^{\circ} 13^{\prime} 59^{\prime \prime} \mathrm{N}-\right.$ $\left.34^{\circ} 37^{\prime} 36^{\prime \prime} \mathrm{N}, 122^{\circ} 16^{\prime} 25^{\prime \prime} \mathrm{W}-122^{\circ} 34^{\prime} 56^{\prime \prime} \mathrm{W}\right)$, region $d\left(35^{\circ} 19^{\prime} 3^{\prime \prime} \mathrm{N}-34^{\circ} 29^{\prime} 2^{\prime \prime} \mathrm{N}, 122^{\circ} 11^{\prime} 36^{\prime \prime} \mathrm{E}-\right.$ $120^{\circ} 39^{\prime} 20^{\prime \prime} \mathrm{E}$ ) and threshold selection (take landsat 8 as an example, to do histogram distribution of mixed patches and pure seawater patches) 
Table 2. Distribution of 12 sub-areas

\begin{tabular}{l|c|c}
\hline & Longitude & Latitude \\
\hline Region 1 & $120^{\circ} 53^{\prime} 50^{\prime \prime}-121^{\circ} 16^{\prime} 17$ & $35^{\circ} 7^{\prime} 34^{\prime \prime}-35^{\circ} 20^{\prime} 31^{\prime \prime}$ \\
Region 2 & $120^{\circ} 53^{\prime} 37^{\prime \prime}-121^{\circ} 18^{\prime} 56^{\prime \prime}$ & $34^{\circ} 44^{\prime} 5^{\prime \prime}-34^{\circ} 50^{\prime} 99^{\prime \prime}$ \\
Region 3 & $121^{\circ} 28^{\prime} 17^{\prime \prime}-121^{\circ} 50^{\prime} 42^{\prime \prime}$ & $35^{\circ} 4^{\prime} 15^{\prime \prime}-35^{\circ} 10^{\prime} 30^{\prime \prime}$ \\
Region 4 & $121^{\circ} 49^{\prime} 29^{\prime \prime}-122^{\circ} 13^{\prime} 72^{\prime \prime}$ & $34^{\circ} 43^{\prime} 20^{\prime \prime}-35^{\circ} 6^{\prime} 41^{\prime \prime}$ \\
Region 5 & $121^{\circ} 9^{\prime} 57^{\prime \prime}-121^{\circ} 34^{\prime} 22^{\prime \prime}$ & $34^{\circ} 50^{\prime} 17^{\prime \prime}-34^{\circ} 59^{\prime} 12^{\prime \prime}$ \\
Region 6 & $121^{\circ} 25^{\prime} 3^{\prime \prime}-121^{\circ} 37^{\prime} 1^{\prime \prime}$ & $34^{\circ} 44^{\prime} 29^{\prime \prime}-34^{\circ} 53^{\prime} 55^{\prime \prime}$ \\
Region 7 & $121^{\circ} 27^{\prime} 28^{\prime \prime}-121^{\circ} 46^{\prime} 20^{\prime \prime}$ & $35^{\circ} 6^{\prime} 29^{\prime \prime}-35^{\circ} 22^{\prime} 20^{\prime \prime}$ \\
Region 8 & $121^{\circ} 10^{\prime} 6^{\prime \prime}-121^{\circ} 36^{\prime} 40^{\prime \prime}$ & $34^{\circ} 40^{\prime} 54^{\prime \prime}-34^{\circ} 51^{\prime} 25^{\prime \prime}$ \\
Region 9 & $121^{\circ} 20^{\prime} 27^{\prime \prime}-121^{\circ} 30^{\prime} 29^{\prime \prime}$ & $34^{\circ} 46^{\prime} 59^{\prime \prime}-35^{\circ} 7^{\prime} 28^{\prime \prime}$ \\
Region 10 & $121^{\circ} 43^{\prime} 57^{\prime \prime}-122^{\circ} 0^{\prime} 59^{\prime \prime}$ & $34^{\circ} 46^{\prime} 10^{\prime \prime}-34^{\circ} 55^{\prime} 26^{\prime \prime}$ \\
Region 11 & $120^{\circ} 48^{\prime} 22^{\prime \prime}-121^{\circ} 4^{\prime} 46^{\prime \prime}$ & $34^{\circ} 45^{\prime} 20^{\prime \prime}-34^{\circ} 55^{\prime} 7^{\prime \prime}$ \\
Region 12 & $121^{\circ} 31^{\prime} 48^{\prime \prime}-121^{\circ} 45^{\prime} 42^{\prime \prime}$ & $34^{\circ} 55^{\prime} 17^{\prime \prime}-35^{\circ} 1^{\prime} 27^{\prime \prime}$ \\
\hline
\end{tabular}

Table 3 compares the area of the algae in each of the 12 sub-areas detected by each optical sensor. We use the following form (e.g. Eq. 9) to compare the accuracy of different sensor algal detection areas:

$$
\epsilon=\frac{\mathrm{s}-\mathrm{s}_{\mathrm{m}}}{s_{m}}
$$

where $\mathrm{S}$ is the area statistics of each sensor detecting algae, $\mathrm{S}_{\mathrm{m}}$ is the area "true value", and the algorithm will take the result of GF1/WFV as the "true value". The regression analysis of the area results of each sensor detection is shown in Figure 5. Based on the GF1 data of $16 \mathrm{~m}$ resolution, the average accuracy of algal area in different sub-areas extracted from landsat 8 with a resolution of $30 \mathrm{~m}$ is $5.62 \%$, and the statistical area was about 1.05 times that of GF1 result. The average precision of algal area in different subareas extracted from Sentinel3 with $300 \mathrm{~m}$ resolution was $92.9 \%$, and the statistical area was about 1.7 times that of GF1 result. The average precision of algal area in different sub-areas extracted from GOCI with a resolution of $500 \mathrm{~m}$ was $172.28 \%$, and the statistical area was about 2.3 times that of GF1 result. The average precision of algal area in different sub-areas extracted from MODIS with $1000 \mathrm{~m}$ resolution is $253.28 \%$, and the statistical area is about 3 times that of GF1 result.

From the statistical results of the algal area in the 12 sub-regions of the Table 3, it can be seen that the spatial resolution of the satellite sensor is the main reason that affects the detection area of the green macroalgae bloom. The lower the spatial resolution, the higher the detection area. The $16 \mathrm{~m}$ resolution GF1 data is similar to the $30 \mathrm{~m}$ resolution Landsat8 data inversion of the algae, and is also the closest to the real value. The $1000 \mathrm{~m}$ resolution MODIS data inversion has the largest area and the lowest precision, and the overestimated error is generated relative to the $16 \mathrm{~m}$ resolution GF1 data. This overestimation problem can be mitigated by using mixed pixel decomposition, but it cannot be completely solved. In addition to spatial resolution, there are other factors that affect the detection area of bloom. There may be performance impact of the sensor itself, or due to the small difference in transit time between the various sensors. Due to the influence of environmental factors such as 
wind, flow and temperature on the sea surface, the dynamic change of this event is large, and it is difficult to accurately register between different sensors. Smaller time differences may result in changes in the biomass of the algae or algal patches rise and fall, causing deviations in pixel recognition.

Table 3. Algal statistical results of 12 sub-areas $\left(\mathrm{km}^{2}\right)$

\begin{tabular}{c|c|c|c|c|c}
\hline & Landsat8/OLI & sentinel-3/OLCI & COMS/GOCI & Aqua/MODIS & GF1/WFV \\
\hline Region 1 & 4.677 & 7.584 & 11.441 & 16.863 & 4.217 \\
Region 2 & 6.676 & 11.223 & 15.584 & 19.2183 & 6.226 \\
Region 3 & 3.287 & 6.553 & 9.618 & 12.229 & 3.045 \\
Region 4 & 3.582 & 6.537 & 10.708 & 14.437 & 3.395 \\
Region 5 & 7.951 & 13.387 & 15.101 & 23.484 & 7.353 \\
Region 6 & 2.783 & 6.568 & 9.301 & 10.290 & 2.730 \\
Region 7 & 4.415 & 7.442 & 11.478 & 17.290 & 4.273 \\
Region 8 & 8.088 & 13.328 & 15.588 & 21.729 & 8.085 \\
Region 9 & 8.179 & 12.061 & 15.650 & 20.568 & 7.542 \\
Region 10 & 2.887 & 6.874 & 8.016 & 9.586 & 2.731 \\
Region 11 & 4.612 & 7.093 & 11.475 & 14.233 & 4.286 \\
Region 12 & 2.717 & 5.620 & 9.129 & 10.219 & 2.698 \\
\hline
\end{tabular}

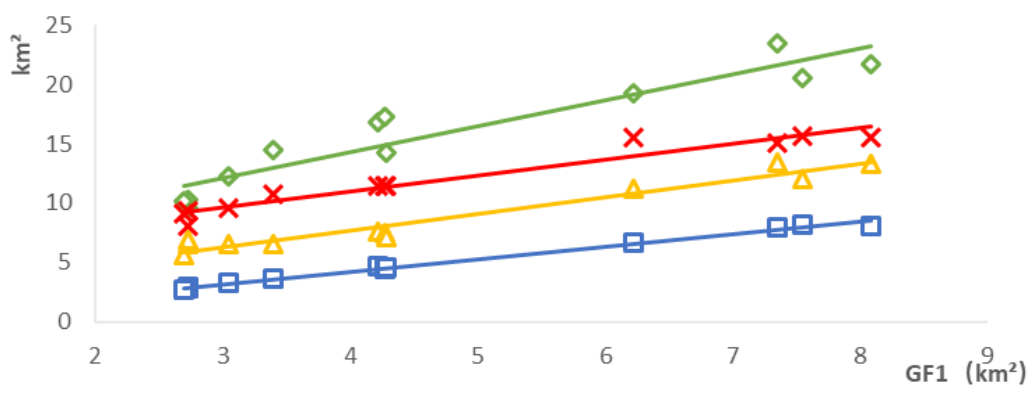

Figure 5. Regression analysis of each sensor and GF1 sub-areas. Landsat8 (blue), MODIS (green), GOCI (red), sentinel3 (yellow)

We selected a small area and used MODIS/Aqua, COMS/GOCI, Sentinel-3/OLCI, Landsat8/OLI and GF1/WFV data to perform NDVI calculations. The results of qualitative bloom detection are shown in Figure 6. Compared with the results of five different spatial resolutions of algae, the MODIS data with $1000 \mathrm{~m}$ resolution can only roughly reflect the drift direction of this bloom. The $500 \mathrm{~m}$ resolution GOCI and $300 \mathrm{~m}$ resolution Sentinel-3 data mostly show the jagged shape due to pixel mosaic. The Landsat 8 data at $30 \mathrm{~m}$ resolution and the GF1 data at $16 \mathrm{~m}$ resolution can show a strip-like bloom drift path, showing more algae details. The higher the spatial resolution, the more detail the observable algal patches are, and the shape of the algal patches is more defined.

\section{Comparison of $U$. prolifera bloom detection algorithm}

The selection time was May 27, 2017, and the data of MODIS/Aqua, COMS/GOCI, Sentinel-3/OLCI, Landsat8/OLI, and GF1/WFV were used to invert the $U$. prolifera patches in the study area. Qualitative detection of blooming event used the spectral band 
difference algorithms and the band-ratio algorithms. The band-ratio algorithm is represented by NDVI, and the spectral band difference algorithm is represented by FAI and MGTI. Only a few ocean color sensors have the spectral requirements to meet the algorithm. Sentinel-3/OLCI, GF1/WFV, COMS/GOCI and other sensor bands are limited, while MODIS/Auqa and Landsat8/OLI can provide more spectral segments, so Sentinel-3/OLCI, GF1/WFV, COMS/GOCI take the MGTI as an example when the spectral band difference algorithm is used. For the spectral band difference algorithm of MODIS/Auqa and Landsat8/OLI, FAI is taken as an example.
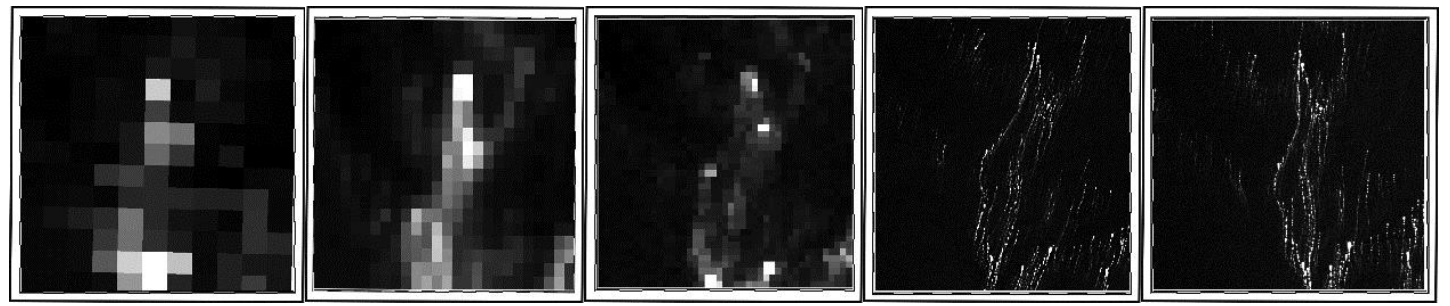

Figure 6. From left to right, MODIS, GOCI, Sentinel3, Landsat8, GF1 NDVI detection results.

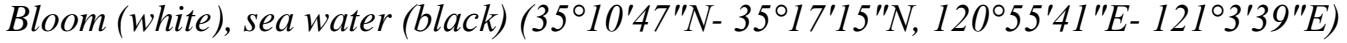

The results of the algal area of the study area calculated by each sensor are shown in Table 4. The spectral band difference algorithm of the single sensor is consistent with the area statistical result of the band-ratio algorithm, and the reliability of the extraction result is also confirmed to some extent. As shown in Figure 7, each sensor qualitatively detects the blooming distribution in the study area. Under the same sensor condition, the results of qualitative detection of algae by different optical algorithms are highly consistent. Compared with the band-ratio algorithm, the spectral band difference algorithm is less sensitive to observation conditions and environment, and can be seen through the "thin cloud".

\section{U. prolifera bloom dynamic monitoring}

Different time intervals for repeated observations of fixed areas on the ground by different ocean color sensors, plus cloud cover and other factors will affect the continuous and effective detection of bloom. The time resolutions of the five satellite sensors are different. The revisit time of GF1 is 4 days, the revisit time of Landsat 8 is 16 days, the revisit time of Sentinel3 is less than two days, the revisit time of GOCI is $1 \mathrm{~h}$, and the revisit time of MODIS is 1 day. Finding the data of each sensor from May to July 2017, and drawing the dynamic bloom drift path, the results indicate that the GOCI data can better detect the dynamic drift of the bloom(e.g. Fig.8 (a) ), which most important reason is that it has the most valid data. The widths of MODIS, Sentinel3, and GOCI are large, and they can cover most areas where the algae, but MODIS and Sentinel3 have less available data compared with GOCI (e.g. Fig. $8(b, c)$ ). Landsat8, GF1, and Sentinel3 have small time resolution and less available data (GF1, Landsat is not shown in the figure because the data volume is too small), and because GOCI is a geostationary orbit sensor, compared to the other four sensors, it eliminates the effect of orbital movement and can efficiently target areas of interest probe. Although the time resolution of MODIS data is large, it is not recommended to use it for dynamic monitoring of algae due to the impact of cloud coverage and low spatial resolution. 
The cloudless GOCI image or GOCI images with few clouds in time range were selected from the Korean Ocean Satellite website. After preprocessing the images, the NDVI method was selected to extract the algal information. This study selected 6 days of yellow sea green algae bloom detection results on May 17, 2017, May 26, 2017, May 28, 2017, June 14, 2017, June 27, 2017 and July 12, 2017 for display.

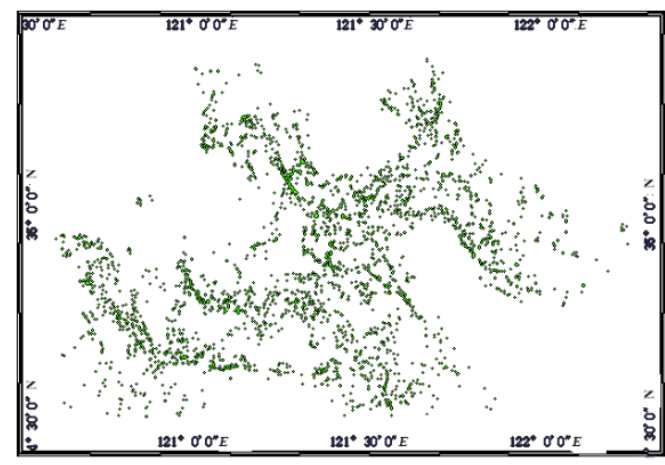

(a1) GF1/WFV NDVI results

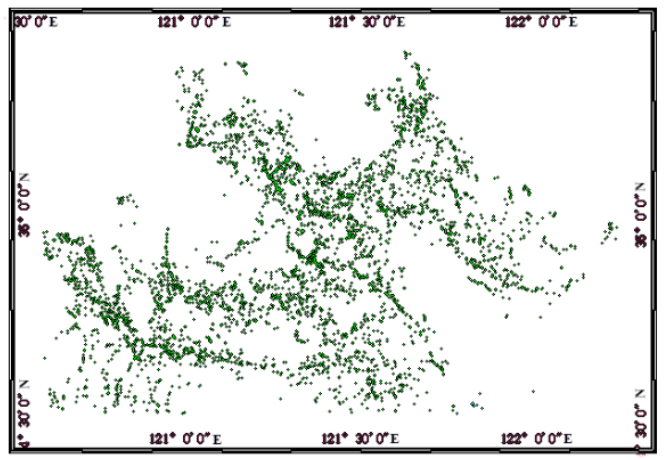

(b1) Landsat8/OLI NDVI results

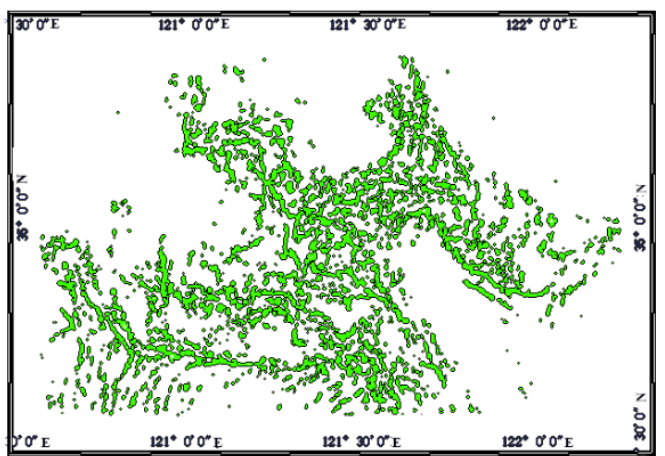

(c1) sentinel3/OLCI NDVI results

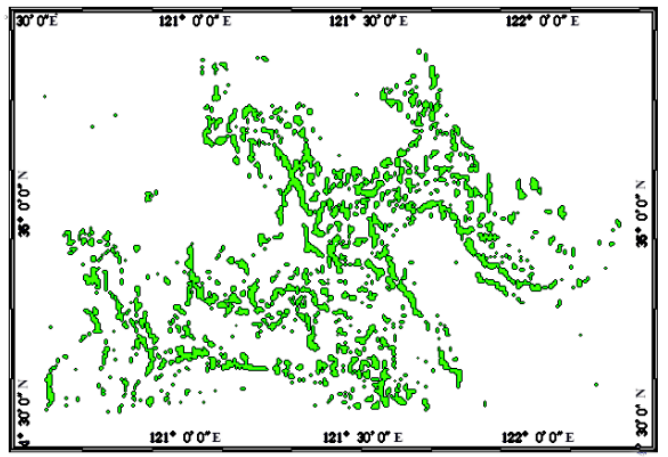

(d1) COM/GOCI NDVI results

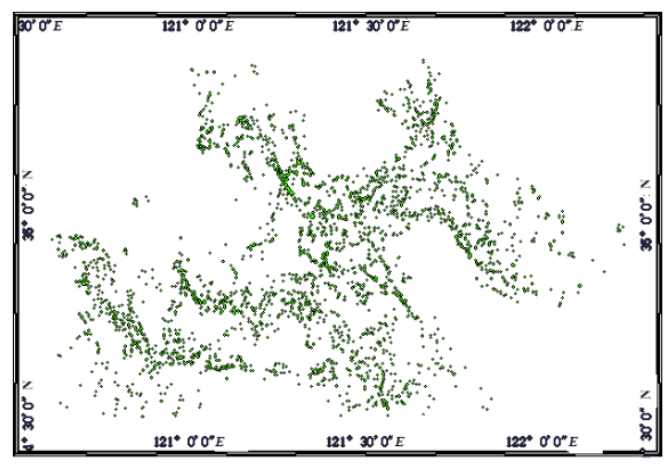

(a2) GF1/WFV MGTI results

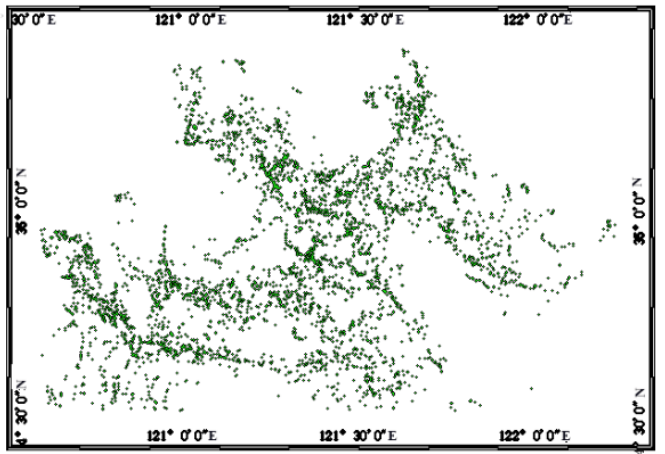

(b2) Landsat8/OLI FAI results

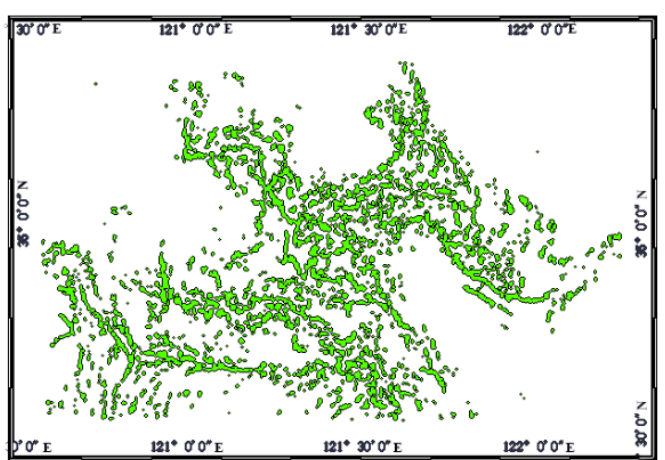

(c2) sentinel3/OLCI MGTI results

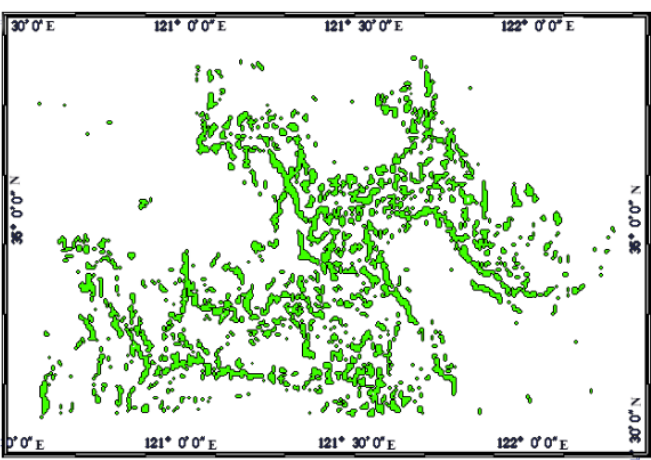

(d2) COM/GOCI MGTI results 


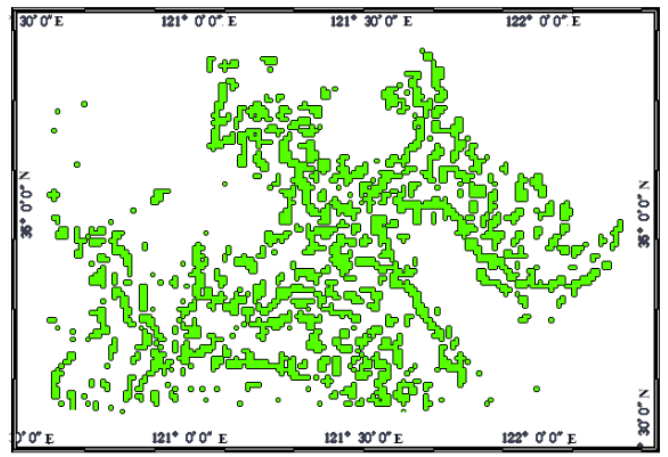

(e1) Aqua/MODIS NDVI results

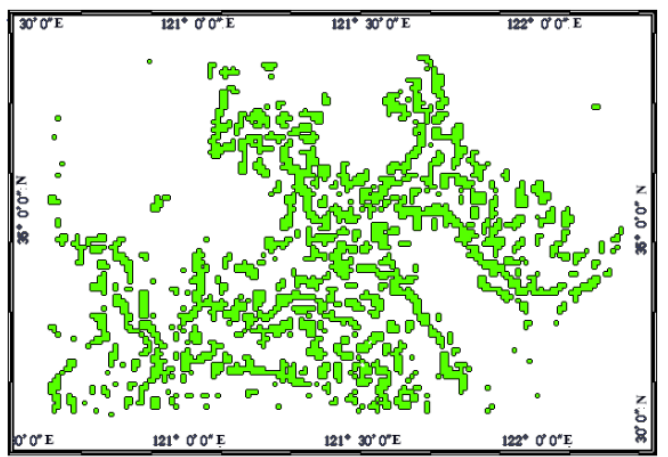

(e2) Aqua/MODIS FAI results

Figure 7. Qualitative monitoring results of each sensor
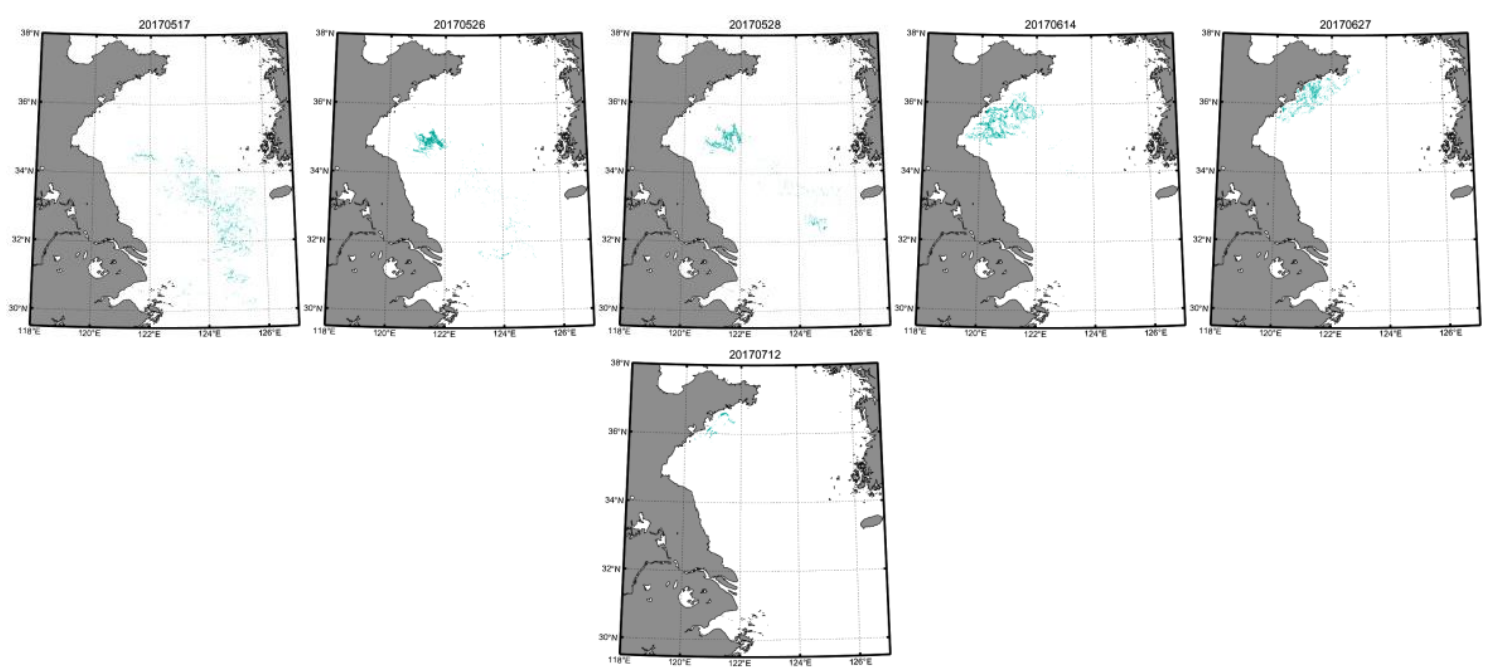

(a) Dynamic drift distribution of bloom obtained from GOCI data
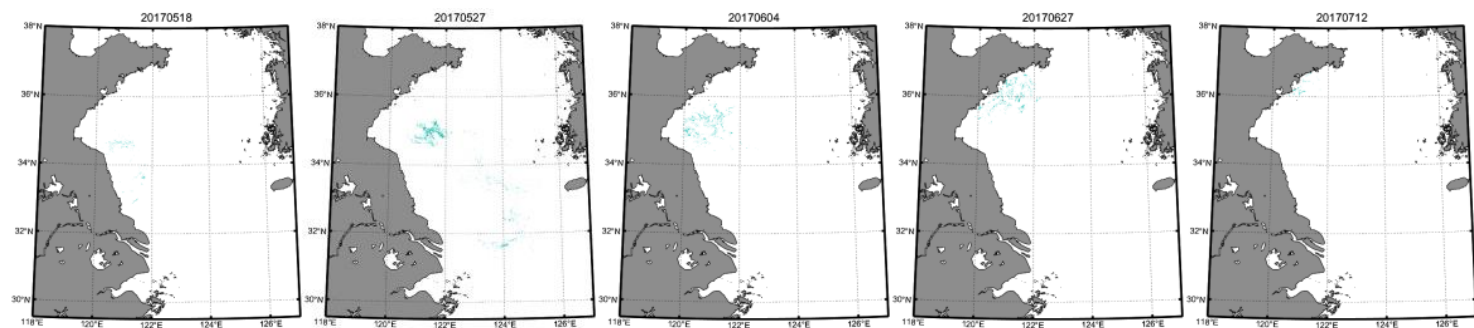

(b) Dynamic drift distribution of bloom obtained from Sentinel3 data

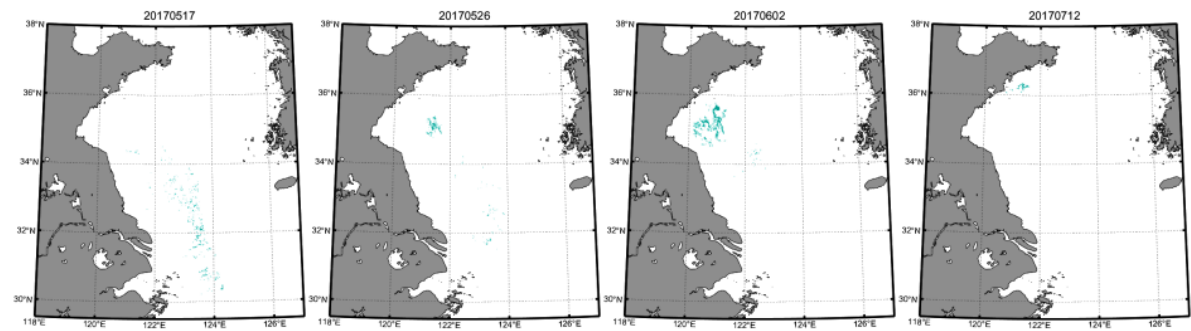

(c) Dynamic drift distribution of bloom obtained from Sentinel3 data

Figure 8. U. prolifera distribution map from May to July 2017 obtained from GOCI, Sentinel3 and MODIS respectively 
Table 4. Statistical results of U. prolifera patches area in the study area

\begin{tabular}{c|c|c|c}
\hline Instrument & Method & Spatial resolution $(\mathbf{m})$ & Area statistics results $\left.\mathbf{( k m}^{\mathbf{2}}\right)$ \\
\hline GF1/WFV & NDVI & 16 & 40.939 \\
Landsat8/OLI & NDVI & 30 & 43.378 \\
Sentinel-3/OLCI & NDVI & 300 & 81.322 \\
COMS/GOCI & NDVI & 500 & 87.266 \\
Aqua/MODIS & NDVI & 1000 & 128.708 \\
GF1/WFV & MGTI & 16 & 41.549 \\
Landsat8/OLI & FAI & 30 & 43.399 \\
Sentinel-3/OLCI & MGTI & 300 & 80.547 \\
COMS/GOCI & MGTI & 500 & 83.903 \\
Aqua/MODIS & FAI & 1000 & 130.55 \\
\hline
\end{tabular}

The composites of algae and sea surface wind are shown in Figure 9, it indicates the numerical simulation of the sea surface wind has a high correlation with the movement of the macroalgae bloom. A green macroalgae bloom appeared in May and died in July, its drift path is roughly northward along the land.
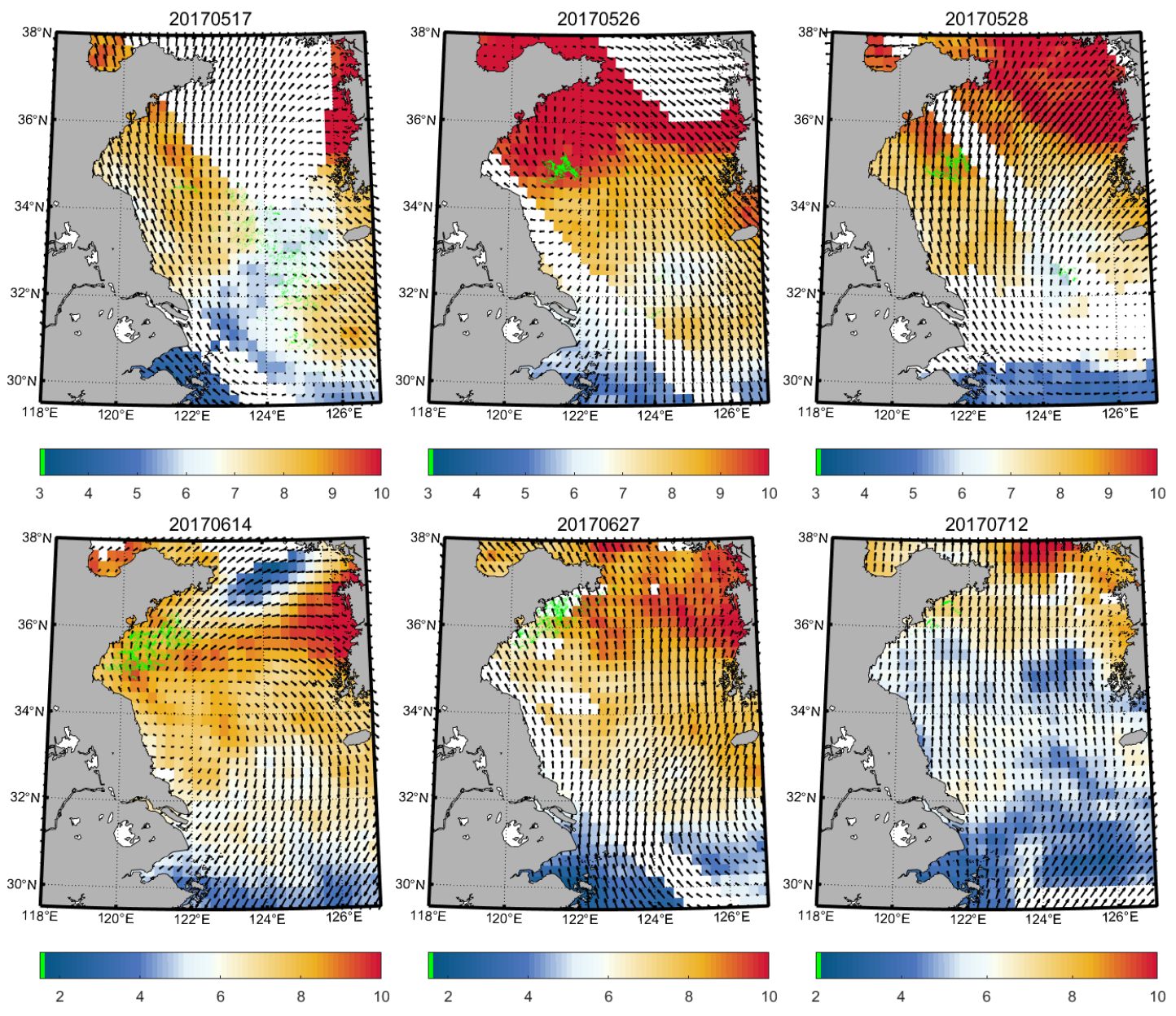

Figure 9. The map of the surface geostrophic current speed (color), velocities (vectors) and algae obtained from GOCI data (green) 
It can be seen from Figure 9 that in May the bloom erupted and moved northward under the transport of prevailing wind (southerly and southeastern wind), that also proves that the prevailing wind is the main driving force for the movement of this event (Xing et al., 2009). Green macroalgae grows rapidly in mid-May, moves northward under the control of environmental factors, and gradually gathers in the waters near Lianyungang, from May 26th to May 28th, the drift speed of the algae was very small and there was almost no drift, which also accorded with the wind direction. The biomass of algae has reached its maximum in mid-June, and it continues to move northward and spreads. In late June and early July, the wind was blowing towards the land, it gradually disappeared due to human fishing and other reasons. A comprehensive analysis of the distribution and the biomass can be found that they are all approximately normal distribution. The distribution of $U$. prolifera is first dispersed, then aggregated and redispersed, and the biomass of algae is first increased and then decreased. This is consistent with the process of emergence, development, outbreak, and extinction of U. prolifera.

\section{Discussion}

In the process of using optical algorithm to detect algae, cloud pixels will cause misjudgment. Cloud pixels are displayed as high values in both FAI and NDVI. If the pixel mosaic shape is just a thin strip, it may be misunderstood as a algae pixel. The current cloud concealing algorithm is very rich, but it does not distinguish the cloud pixel completely. The algorithm of the monitor algae, we can use the RGB image for cross-checking.

More types of sensors and data assimilation methods should be used to establish relevant detection systems to deal with algal outbreaks and reduce the possibility of damage to the marine environment. In addition to optical remote sensing satellites, there are many other platforms that provide data for detecting $U$. prolifera blooms. In recent years, unmanned aerial vehicle (UAV) have become one of the important tools for obtaining high-resolution remote sensing data due to their small size, low operating cost and high flexibility. Some scholars have used UAV to conduct monitoring research on $U$. prolifera disasters. UAV observations can effectively compensate for the lack of spatial resolution and temporal resolution of traditional satellite remote sensing methods in blooming events monitoring. Optical data can detect algae suspended in the sea below a certain depth. Microwave cannot penetrate the sea surface, so it can only detect algal patches floating on the surface. However, microwave remote sensing is not affected by weather conditions and can penetrate the cloud. Microwave data such as SAR images are a good complement to all-weather monitoring of blooming events. Because the imaging mechanism of microwave image and optical image is different, we need a large number of simultaneous optical and microwave data analysis to obtain more accurate results of blooming events detection.

\section{Conclusion}

Since algal blooms is characterized by rapid growth, it is important to monitor potential algae bloom events early through satellite data. For qualitative monitoring of $U$. prolifera bloom, the use of optical algorithms for detection is reliable, and the results of the band-ratio algorithm and the spectral band difference algorithm are similar. It is important to accurately target the bands of green vegetation, the higher the spectral 
resolution data, the better the qualitative algae patches. For quantitative monitoring of $U$. prolifera bloom, the results of low spatial resolution data detection of area are too large, which attempted to use the mixed pixel decomposition to calculate the area to weaken the overestimation phenomenon, but this overestimation cannot be eliminated. For effective monitoring and forecasting to save time, it is recommended to use high spatial resolution sensors, of course sensor revisit time (related to the detection time interval) and the width of the image (related to the detection range) are important. Sea surface wind determines the dynamic movement direction of algae. Using satellite data numerical simulation to monitor the state of sea surface wind can effectively monitor the drift of green macroalgae.

Acknowledgements. This work was supported by the National Key R\&D Program of China [Grant numbers 2017YFC1404100, 2017YFC1404104]; the Key R\&D Program of Shandong [Grant numbers 2019GHY112049]; Scientific Research Foundation of Shandong University of Science and Technology for Recruited Talents [Grant numbers 2015RCJJ016]; National Natural Science Foundation of China (Grant numbers 41576024); Guangxi Key R\&D Program (Project Contract numbers: Gui ke AB16380282).

\section{REFERENCES}

[1] Baret, F., Guyot, G. (1991): Potentials and limits of vegetation indices for LAI and APAR assessment. - Remote Sensing of Environment 35: 161-173.

[2] Blondeau-Patissier, D., Gower, J. F., Dekker, A. G., Phinn, S. R., Brando, V. E. (2014): A review of ocean color remote sensing methods and statistical techniques for the detection, mapping and analysis of phytoplankton blooms in coastal and open oceans. Progress in Oceanography 123: 123-144.

[3] Cui, T. W., Zhang, J., Sun, L. E., Jia, Y. J., Zhao, W., Wang, Z. L., Meng, J. M. (2012): Satellite monitoring of massive green macroalgae bloom (GMB): imaging ability comparison of multi-source data and drifting velocity estimation International. - Journal of Remote Sensing 33: 5513-5527.

[4] Garcia, R. A., Fearns, P., Keesing, J. K., Liu, D. (2013): Quantification of floating macroalgae blooms using the scaled algae index. - Journal of Geophysical Research: Oceans 118: 26-42.

[5] Gower, J., King, S., Borstad, G., Brown, L. (2005): Detection of intense plankton blooms using the $709 \mathrm{~nm}$ band of the MERIS imaging spectrometer. - International Journal of Remote Sensing 26: 2005-2012.

[6] Hu, C. (2009): A novel ocean color index to detect floating algae in the global oceans. Remote Sensing of Environment 113: 2118-2129.

[7] Hu, C., He, M. X. (2008): Origin and offshore extent of floating algae in Olympic sailing area. - Eos, Transactions American Geophysical Union 89: 302-303.

[8] Hu, C., Cannizzaro, J., Carder, K. L., Muller-Karger, F. E., Hardy, R. (2010a): Remote detection of Trichodesmium blooms in optically complex coastal waters: examples with MODIS full-spectral data. - Remote Sensing of Environment 114: 2048-2058.

[9] Hu, C., Li, D., Chen, C., Ge, J., Muller-Karger, F. E., Liu, J., He, M. X. (2010b): On the recurrent Ulva prolifera blooms in the Yellow Sea and East China Sea - Journal of Geophysical Research: Oceans 115: C5.

[10] Keesing, J. K., Liu, D., Fearns, P., Garcia, R. (2011): Inter- and intra-annual patterns of Ulva prolifera green tides in the Yellow Sea during 2007-2009, their origin and relationship to the expansion of coastal seaweed aquaculture in China. - Marine pollution bulletin 62: 1169-1182. 
[11] Li, S., Li, W. Z., Zhou, J. J., Zhuang, D. F. (2007): A review on endmember selection methods in the course of mixed pixel decomposition of remote sensing images. Geography and Geo-Information Science 23(5): 35-38.

[12] Liang, Z., Lin, X., Ma, M., Zhang, J., Yan, X., Liu, T. (2008): A preliminary study of the Enteromorpha prolifera drift gathering causing the green tide phenomenon. - Periodical of Ocean University of China 38: 601-604.

[13] Liu, D., Keesing, J. K., Xing, Q., Shi, P. (2009): World's largest macroalgal bloom caused by expansion of seaweed aquaculture in China. - Marine Pollution Bulletin 58: 888-895.

[14] Naihao, T. Q. Z. X. Y., Zhimeng, Z. (2010): Review on the research progress on marine green tide. - Bulletin of National Natural Science Foundation of China 1: 5-9.

[15] Rouse, J. W., Haas, R. H., Schell, J. A., Deering, D. W. (1974): Monitoring vegetation systems in the Great Plains with ERTS. - NASA special publication 1974: 351-309.

[16] Shi, W., Wang, M. (2009): Green macroalgae blooms in the Yellow Sea during the spring and summer of 2008. - Journal of Geophysical Research 114: C12.

[17] Shimada, S., Yokoyama, N., Arai, S., Hiraoka, M. (2008): Phylogeography of the Genus Ulva (Ulvophyceae, Chlorophyta), with Special Reference to the Japanese Freshwater and Brackish Taxa. - In: Borowitzka, M. A. et al. (eds.) Nineteenth International Seaweed Symposium, 2008. Springer, Dordrecht, pp. 529-539.

[18] Tan, X., Yu, X. C., Zhang, P. (2013): A classification algorithm for hyperspectral images based on fuzzy mixed pixel decomposition. - Journal of Geomatics Science and Technology 30: 279-283.

[19] Xiao, Y. F., Zhang, J., Cui, T. W., Gong, J. L., Xia, S. Z., Liu, R. J., Mu, B (2017): Spectral characteristics and estimation models of floating green tide biomass on sea surface. - Acta Optica Sinica 37(4): 338-346.

[20] Xing, Q., Loisel, H., Schmitt, F., Shi, P., Liu, D., Keesing, J. (2009): Detection of the green tide at the Yellow Sea and tracking its wind-forced drifting by remote sensing. EGU General Assembly Conference Abstracts 11: 577.

[21] Zhang, H., Sun, D., Li, J., Qiu, Z., Wang, S., He, Y. (2016): Remote sensing algorithm for detecting green tide in China coastal waters based on GF1-WFV and HJ-CCD data. Acta Optica Sinica 36: 28-36. 